\title{
Fator de disponibilidade de água no solo e adubação nitrogenada para a cultura da beterraba
}

\author{
Paulo Henrique de SOUSA FILHO ${ }^{*}$, Flávia DONATO ${ }^{1}$, Maria Elisângela Ferreira de OLIVEIRA ${ }^{1}$, \\ Márcio José de SANTANA ${ }^{1}$, Daniel Pena PEREIRA ${ }^{1}$ \\ ${ }^{1}$ Instituto Federal do Triângulo Mineiro, Uberaba, MG, Brasil. \\ *E-mail: paulohsf99@gmail.com \\ (Orcid: 0000-0001-6558-8579; 0000-0001-6639-1823; 0000-0002-8018-6399; 0000-0003-1985-6880; 0000-0002-4964-0426)
}

Recebido em 13/01/2021; Aceito em 15/06/2021; Publicado em 25/06/2021.

\begin{abstract}
RESUMO: A cultura da beterraba está entre as hortaliças mais consumidas. Dentre os tratos culturais, a irrigação e a adubação são fatores primordiais para uma boa produtividade. Objetivou-se com esse trabalho avaliar o rendimento da beterraba em função de déficits hídricos (fator de disponibilidade hídrica no solo fator f) e doses de N. Para isso, conduziu-se o experimento em blocos casualizados (DBC) com dezesseis tratamentos e quatro repetições, em esquema fatorial $4 \times 4$, sendo quatro fatores $\mathrm{f}(0,1 ; 0,3 ; 0,5$ e 0,7$)$, e quatro doses de N (50,100, 150 e $\left.200 \mathrm{~kg} \mathrm{ha}^{-1}\right)$. Para as variáveis massa seca de raízes, produtividade e sólidos solúveis totais (SST) das raízes, foram observadas diferenças estatísticas significativas. Dentre os resultados pode-se verificar que a dose de $150 \mathrm{~kg} \mathrm{ha}^{-1}$ de $\mathrm{N}$ proporcionou maior acúmulo de nitrogênio foliar; a dose de $150 \mathrm{~kg}$ $\mathrm{ha}^{-1}$ de $\mathrm{N}$ conjuntamente ao fator 0,3 proporcionaram maior teor de SST nas raízes; e, por fim, o fator $\mathrm{f} 0,7$ associado à dose de $200 \mathrm{~kg} \mathrm{ha}^{-1}$ de $\mathrm{N}$ proporcionaram a maior produtividade.
\end{abstract}

Palavras-chave: manejo de irrigação; economia de água; eficiência do uso da água; déficit hídrico.

\section{Soil water availability factor and nitrogen fertilization for beet culture}

\begin{abstract}
The beet crop is among the most consumed vegetables. Amidst cultural tracts, the irrigation and the fertilizing are primordial factors for a good productivity. The objective of this work was to evaluate the yield of beets according to water deficits (water availability factor $-\mathrm{f}$ factor) and $\mathrm{N}$ doses. For this, the experiment was carried out in randomized complete block design (RCBD) with sixteen treatments and four replications, in a $4 \times 4$ factorial scheme, being four $\mathrm{f}$ factors $(0,1 ; 0,3 ; 0,5$ and 0,7$)$ and four $\mathrm{N}$ doses $(50,100,150$ and $\left.200 \mathrm{~kg} \mathrm{ha}^{-1}\right)$. For the roots' dry mass analysis, productivity and roots' total soluble solids (TSS), were observed significant statistical differences. Among the results is possible verify that the $150 \mathrm{~kg} \mathrm{ha}^{-1}$ of N dose provided greater accumulation of leaf nitrogen; the $150 \mathrm{~kg} \mathrm{ha}^{-1}$ of $\mathrm{N}$ dose jointly the 0.3 factor provided higher content of TSS in the roots; and, finally, the 0.7 factor associated with the $200 \mathrm{~kg} \mathrm{ha}^{-1}$ of $\mathrm{N}$ dose provided the greatest productivity.
\end{abstract}

Keywords: irrigation management; water economy; water use efficiency; water deficit.

\section{INTRODUÇÃO}

O consumo de hortaliças pela população é crescente e cada vez mais fica exigente o consumidor, em produto de qualidade. Dentre as hortaliças está a beterraba (Beta vulgaris L), que é uma raiz tuberosa de formato globular que se desenvolve quase superficialmente no solo (RESENDE; CORDEIRO, 2007). Tal cultura se destaca nutricionalmente, sendo rica em ferro e vitaminas, o que consequentemente gera grande demanda do mercado mundial, sobretudo Brasil (SEBRAE, 2011).

Para manter a produtividade alta, com o uso da água ecologicamente correta e racional, os projetos de irrigação junto ao manejo, têm o desafio de produzir nas mesmas áreas e com menor lâmina de água, resultados em produtividades superiores aos cultivos antecessores (SOUZA et al., 2011). Esta também é uma preocupação dos produtores, o que eficiência dos adubos aplicados, juntamente com a água, minimizando perdas de nutrientes por lixiviação, erosão e volatilização (SOUZA et al., 2011).

Dentre os nutrientes disponibilizados para as plantas o nitrogênio $(\mathrm{N})$ é um dos mais significativos, por exercer permite o interesse pelo manejo adequado visando a eficiência do uso da água (CARVALHO et al., 2011).

O manejo de irrigação bem aplicado, principalmente em cultura com exigência maior na disponibilidade hídrica, no tempo e quantidades corretas, potencializa o desenvolvimento das plantas e as mesmas vão responder em produtividade e qualidade (COSTA et al., 2012). Ao irrigar corretamente a área e sempre observando a eficiência do uso da água (EUA), é possível quantificar a produtividade em relação à lâmina que são aplicadas durante o ciclo da cultura (MELO et al., 2010).

A adubação visa incrementar produtividade, pois fornece quantidades de nutrientes necessárias para o desenvolvimento da cultura durante o ciclo. Práticas como o manejo da adubação, são utilizadas no propósito de maior várias funções estruturais e fazer parte de diversos compostos que eleva a resistência ao estresse hídrico (PARIDA; DAS, 2005). Outra importância do N é sua participação nas rotas metabólicas das plantas como proteínas, clorofila, ácidos nucleicos, enzimas, ATP, NADH e NADPH. Ainda 
incrementa na produtividade de diversas culturas, inclusive das hortaliças (ESPIDULA et al., 2010; GOMES et al., 2012).

Desta forma, a água e a adubação nitrogenada são fatores de importância na agricultura para o bom desenvolvimento das plantas, e, quando há déficit desses, a cultura expressa no não desenvolvimento e crescimento (LOPES et al., 2011).

Portanto, o objetivo do trabalho foi avaliar a altura das plantas; teor de $\mathrm{N}$ foliar; diâmetro, massa seca, $\mathrm{pH}$, sólidos solúveis totais e acidez total titulável das raízes; e produtividade da beterraba em função do fator de disponibilidade hídrica no solo e doses de nitrogênio.

\section{MATERIAL E MÉTODOS}

O experimento foi conduzido em área experimental do setor de Culturas Anuais do Instituto Federal do Triângulo
Mineiro de Educação, Ciências e Tecnologia - Campus Uberaba - MG. Localizado a $795 \mathrm{~m}$ de altitude, com latitude de 19³9' 19' S e longitude de 47057' 27' W. O clima do local, segundo classificação de Köppen é do tipo tropical quente e úmido, com inverno frio e seco (Aw), com precipitação, temperatura média anual e umidade relativa média de $1600 \mathrm{~mm}$ e $22,6^{\circ} \mathrm{C}$ e $68 \%$, respectivamente (TORRES, 2005).

Foi realizada a análise química do solo (Tabela 1) junto ao laboratório de Análise de Solo da EPAMIG situado no município de Uberaba - MG.

$\mathrm{O}$ solo da área experimental pertence à classe textural Franco Arenosa, cujas características químicas foram analisadas pelo Laboratório de Análise do Solo da EPAMIG em Uberaba. Os resultados estão apresentados na Tabela 2.

Tabela 1. Resultados da análise química do solo (camada de 0 - $20 \mathrm{~cm}$ ) da área experimental. IFTM - Uberaba - MG, 2019.

Table 1. Results of the soil chemical analysis $(0-20 \mathrm{~cm}$ layer $)$ of the experimental area. IFTM Uberaba - MG, 2019.

\begin{tabular}{|c|c|c|c|c|c|c|c|c|c|c|c|c|}
\hline $\mathrm{pH}$ & $\mathrm{Al}$ & $\mathrm{Ca}$ & $\begin{array}{l}\mathrm{Mg} \\
-\mathrm{Cn}\end{array}$ & $\begin{array}{l}\mathrm{H}+\mathrm{Al} \\
\mathrm{dm}^{-3}-\end{array}$ & SB & $\mathrm{t}$ & $\mathrm{T}$ & $\begin{array}{l}K \\
-n\end{array}$ & $\begin{array}{c}P \\
n^{-3}-\end{array}$ & $\begin{array}{l}\text { P-rem } \\
\mathrm{mg} \mathrm{L}^{-1}\end{array}$ & $\begin{array}{l}V \quad m \\
--\% \text {-- }\end{array}$ & $\begin{array}{c}\mathrm{MO} \\
\text { dag kg-1 }\end{array}$ \\
\hline 6,7 & 0 & 1,7 & 0,5 & 1,6 & 2,4 & 2,4 & 4 & 75 & 25,2 & 30,6 & 59,9 & 1,2 \\
\hline
\end{tabular}

Nota: $\mathrm{Al}=$ alumínio; $\mathrm{Ca}=$ cálcio; $\mathrm{Mg}=$ magnésio; $\mathrm{H}=$ hidrogênio; $\mathrm{SB}=$ soma de bases; $\mathrm{t}=\mathrm{CTC}$ efetiva; $\mathrm{T}=\mathrm{CTC}$ a $\mathrm{pH}$ 7,0; $\mathrm{K}=$ potássio; $\mathrm{P}=$ fósforo; $\mathrm{P}-$ rem = fósforo remanescente; $\mathrm{V}=$ saturação por bases; $\mathrm{m}=$ saturação por alumínio; $\mathrm{MO}=$ matéria orgânica.

Tabela 2. Resultados da análise de textura do solo da área experimental. IFTM - Uberaba - MG, 2019.

Table 2. Results of the soil texture analysis of the experimental area. IFTM - Uberaba - MG, 2019.

\begin{tabular}{|c|c|c|c|c|}
\hline Camada & Areia & Silte & Argila & Classe textural \\
\hline$(\mathrm{cm})$ & & $(\%)$ & & \\
\hline $0-20$ & 74,0 & 8,0 & 18,0 & Franco Arenosa \\
\hline
\end{tabular}

As equações de ajuste das curvas características de retenção de água no solo para as camadas de $0-20$ e $20-40 \mathrm{~cm}$ de profundidade encontram-se na Tabela 3. A obtenção da curva de água no solo foi realizada em amostras deformadas no Laboratório de Relação Solo-Planta do IFTM Câmpus Uberaba, MG. A densidade média do solo para as camadas de $0-20$ e $20-40 \mathrm{~cm}$, obtida pelo método do cilindro de Uhland, forneceu valores de 1,18 e $1,22 \mathrm{~g} \mathrm{~cm}^{-1}$, respectivamente. A umidade correspondente à capacidade de campo é de $0,23 \mathrm{~cm}^{3} \mathrm{~cm}^{-3}$ (tensão de água no solo média de $11 \mathrm{kPa}$ na camada de $0-20 \mathrm{~cm})$ e ponto de murcha permanente de $0,054 \mathrm{~cm}^{3} \mathrm{~cm}^{-3}$ (tensão de água no solo média de $1500 \mathrm{kPa}$ na camada de $0-20 \mathrm{~cm}$ ).

Tabela 3. Resultados da caracterização hídrica do solo da área experimental.

Table 3. Results of soil water characterization in the experimental area.

\begin{tabular}{ccc}
\hline Camada $(\mathrm{cm})$ & Equação & $\mathrm{R}^{2}$ \\
\hline $0-20$ & $\theta=\frac{0,42}{\left[1+\left(1,32 * \psi_{m}\right)^{4,6}\right]^{0,11}}+0,115$ & 0,911 \\
$20-40$ & $\theta=\frac{0,38}{\left[1+\left(0,899 * \psi_{m}\right)^{6,83}\right]^{0,13}}+0,225$ & 0,936 \\
\hline Nota: $\theta=$ umidade volumétrica $\left(\mathrm{cm}^{3} \mathrm{~cm}^{-3}\right) ; \psi^{\prime \prime}=$ potencial matricial $(\mathrm{kPa})$.
\end{tabular}

A cultivar utilizada foi a Tall Top Early Wonder, que apresenta raiz arredondada, variando de 8 a $10 \mathrm{~cm}$ de diâmetro. Seu tipo de semente é cortiçada tendo excelente adaptação a diversas regiões de cultivo, com início da colheita de 65 a 75 dias (AGRISTAR, 2019).

As mudas foram produzidas no Viveiro de mudas Valoriza, em Patos de Minas, MG. O transplante das mudas na área experimental foi realizado no dia 12 de abril de 2019. O experimento foi conduzido em delineamento com blocos casualizados (DBC) com 16 tratamentos, em esquema fatorial de $4 \times 4$ com quatro repetições, totalizando 64 parcelas. Foram estudados quatro reposições de água no solo a partir do fator de disponibilidade hídrica $(0,1 ; 0,3 ; 0,5$ e 0,7$)$ e quatro doses de nitrogênio $\left(50,100,150\right.$ e $\left.200 \mathrm{~kg} \mathrm{ha}^{-1}\right)$.

Cada parcela experimental foi composta por dois canteiros, sendo 3,0 $\mathrm{m}$ de comprimento, 1,1 $\mathrm{m}$ de largura e $0,40 \mathrm{~m}$ entre canteiros. Cada canteiro recebeu linhas duplas de plantio, com espaçamento de 0,30 m entre linhas e $0,10 \mathrm{~m}$ entre mudas. A obtenção da parcela útil foi através da eliminação de $50 \mathrm{~cm}$ das extremidades da parcela, sendo compreendida por um comprimento das linhas de $2,0 \mathrm{~m}$.

Para aplicação dos tratamentos foi adotado um sistema de irrigação por microaspersão, sendo que os emissores foram microaspersor com uma vazão de 87 litros por hora (L $\mathrm{h}^{-1}$ ) com uma pressão de serviço de $20 \mathrm{mca}$. Cada parcela tinha quatro microaspersores, com espaçamento de 1,20 m em cada canteiro, que simulou uma irrigação por aspersão.

Quanto aos fatores de disponibilidade hídrica, foi considerado o intervalo de água no solo entre o ponto de murcha permanente e a capacidade de campo para aplicação de água a partir dos fatores estudados. Assim, os déficits foram em porcentagem: $10 \%$ para o fator $0,1,30 \%$ para o fator $0,3,50 \%$ para o fator 0,5 e $70 \%$ para o fator 0,7 . A partir da estimativa da evapotranspiração diária, a irrigação para cada fator foi determinada quando atingia-se o déficit estipulado. As lâminas aplicadas durante o ciclo foram: 197,$69 ; 153,76 ; 109,83$ e $65,90 \mathrm{~mm}$ para os respectivos fatores f 0,$1 ; 0,3 ; 0,5$ e 0,7 .

Diariamente foi determinado a evapotranspiração de referencia (ETo), para posterior estimativa da evapotranspiração da cultura (ETc) e obtenção das lâminas 
de irrigação. Assim, para obtenção destes valores, foi utilizada a equação de Hargreaves-Samani (1985), identificada como Equação 1.

ETo $=0,0023 \times($ Tméd $+17,8) \times($ Tmáx -

Tmín) $)^{0,5} \times$ Ra x 0,408

em que: ETo = evapotranspiração de referência, em mm/dia; Tméd = temperatura média diária, $\mathrm{em}^{\circ} \mathrm{C} ;$ Tmín $=$ temperatura mínima diária, em ${ }^{\circ} \mathrm{C}$; Tmáx $=$ temperatura máxima diária, em ${ }^{\circ} \mathrm{C} ; \mathrm{Ra}=$

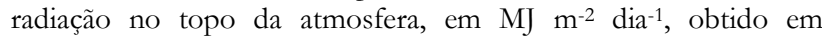
Mantovani, Bernardo e Palaretti (2009).

O cálculo da ETc foi obtido conforme Equação 2:

$$
\mathrm{ETc}=\mathrm{ETo} \times \mathrm{Kc} \times \mathrm{Ks}
$$

em que: ETc $=$ evapotranspiração da cultura, $\mathrm{em} \mathrm{mm} / \mathrm{dia} ; \mathrm{ETo}=$ evapotranspiração de referência, em $\mathrm{mm} \mathrm{dia}{ }^{-1} ; \mathrm{Kc}=$ coeficiente da cultura; $\mathrm{Ks}=$ coeficiente de umidade do solo (adotado 1 para o experimento).

O cálculo da lâmina bruta foi obtido pela Equação 3:

$$
\mathrm{LB}=\mathrm{ETc} / 0,9
$$

em que: LB = lâmina bruta, em mm; ETc = evapotranspiração da cultura.

A adubação foi determinada conforme recomendação da Comissão de Fertilidade do Solo do Estado de Minas Gerais (1999), seguindo os passos agronômicos: a calagem foi feita três meses antes do transplante das mudas; a adubação de plantio foi realizada no dia 11/04/2019, sendo que foram aplicados $60 \%$ de cada dose de N (ureia convencional) de todos os tratamentos em suas respectivas parcelas e os outros $40 \%$ foram aplicados em duas adubações de cobertura, realizadas aos 20 e 43 dias após o transplantio (DAT). A adubação com fósforo (Superfosfato Simples) e boro (B) foi $100 \%$ na adubação no dia 11/04/2019 nas doses de $50 \mathrm{~kg} \mathrm{ha}$ ${ }^{1}\left(\mathrm{P}_{2} \mathrm{O}_{5}\right)$ e $1 \mathrm{~kg} \mathrm{ha}^{-1}$ (B) respectivamente, e por fim, o total de potássio aplicado foi de $50 \mathrm{~kg} \mathrm{ha}^{-1}$ de $\mathrm{K}_{2} \mathrm{O}\left(30 \mathrm{~kg} \mathrm{ha}^{-1}\right.$ no dia 11/04/2019 e $20 \mathrm{~kg} \mathrm{ha}^{-1}$, divididos em duas adubações de cobertura, que foram aos 20 e 43 dias após o transplantio).

As variáveis avaliadas foram: altura de plantas, diâmetro da raiz, massa seca de raízes, teor de $\mathrm{N}$ foliar, $\mathrm{pH}$ das raízes, sólidos solúveis totais das raízes, acidez total titulável das raízes e produtividade.

Foram colhidas seis plantas inteiras de cada parcela aleatoriamente, sendo conduzidas para o laboratório de Bromatologia do IFTM. Posteriormente, foram lavadas com água corrente e seca com papel toalha comum. Foi medida a altura das plantas com uma régua graduada, o diâmetro transversal das raízes utilizando um paquímetro digital e massa seca das raízes em uma balança de precisão.

Após a pesagem das raízes comerciais, as seis raízes por parcelas foram submetidas a secagem em sacos de papel, sendo colocadas em estufa a $65^{\circ} \mathrm{C}$ por 72 horas com circulação forçada, para a obtenção da massa seca. Em seguida, ocorreu a pesagem do material em uma balança de precisão por parcela e tratamentos.

Para a determinação do teor de nitrogênio nas folhas foi seguida a metodologia descrita por Rodela et al. (2007). Foram coletadas manualmente e de forma aleatória aos 62 dias após o transplante, dez folhas do terço médio de dez plantas dentro de cada parcela.

As folhas foram colocadas em sacos de papel e em seguida dentro de uma caixa térmica e encaminhadas para o laboratório de química, localizado em Patos de Minas, MG.

Para as avaliações descritas a seguir, foram selecionadas seis raízes de padrão comercial de cada parcela por tratamentos para as análises. As raízes foram encaminhadas para o laboratório de alimentos do IFTM. As amostras foram lavadas e secas ao ar, cortadas ao meio e raladas em ralador inox. A avaliação do $\mathrm{pH}$ foi através da leitura do pHmetro. Para determinação do teor de sólidos solúveis totais ( ${ }^{\circ} \mathrm{Brix}$ ) no extrato, por meio de um refratômetro digital calibrado e higienizado com etanol, ajustado a temperatura de $25{ }^{\circ} \mathrm{C}$ e seguindo as normas analíticas do Instituto Adolfo Lutz (1985).

$\mathrm{Na}$ determinação da acidez total titulável, utilizou o método acidimétrico da A.O.A.C (1997), por meio de solução padronizada de $\mathrm{NaOH} 0,1 \mathrm{~N}$ e calculado fator de correção. A solução da amostra utilizada possui concentração de $10 \%$. Foram pipetadas $10 \mathrm{~mL}$ da solução em erlenmeyer de 125 $\mathrm{mL}$, adicionado $50 \mathrm{~mL}$ de água destilada e 3 gotas de fenolftaleína. O cálculo da porcentagem de acidez na amostra foi realizado mediante a Equação 4:

$\%$ ácido $=\mathrm{V} \mathrm{NaOH} \times \mathrm{N} \times \mathrm{fc} \times \mathrm{PE} \times\left(\frac{100}{10}\right) \times\left(\frac{1}{1000}\right)$

em que: $\mathrm{V} \mathrm{NaOH}=$ volume gasto de $\mathrm{NaOH}$ gasto na titulação, em $\mathrm{mL} ; \mathrm{N}=$ normalidade; $\mathrm{fc}=$ fator de correção; $\mathrm{PE}=$ peso da beterraba, em $g$.

A produtividade foi obtida pela pesagem da parcela útil de cada parcela, seguido da transformação da pesagem em $t$ $\mathrm{ha}^{-1}$.

Foram realizadas análises de variância para as médias de todos os parâmetros avaliados, utilizando-se o teste $\mathrm{F}$ a $5 \%$ de probabilidade. Para comparação das médias consideradas foi usado teste de regressão. Para essas análises foi utilizado o "software" Sisvar para Windows versão 4.3 (FERREIRA, 2008).

\section{RESULTADOS}

Durante a condução do experimento, o total e a média diária de ETo estimados encontrados foram 258,04 mm e $3,91 \mathrm{~mm} \mathrm{dia}{ }^{-1}$, respectivamente, sendo que esses valores oscilaram de 0,786 a 5,047 $\mathrm{mm} \mathrm{dia}{ }^{-1}$. A ETc estimada acumulada da beterraba teve valores total e média diária de $228,06 \mathrm{~mm}$ e 3,46 $\mathrm{mm} \mathrm{dia}^{-1}$, respectivamente, e as variações durante o desenvolvimento do experimento foi entre 0,393 a $4,79 \mathrm{~mm} \mathrm{dia}^{-1}$.

O somatório da lâmina bruta, correspondente aos diferentes tratamentos, foram de 153,76; 109,83, 65,90 e $21,97 \mathrm{~mm}$, respectivamente para os fatores 0,$7 ; 0,5 ; 0,3$ e 0,1 .

Ao longo do período de experimentação, houve ocorrência de chuvas, distribuídas em 7 dias, conforme a Figura 1. A lâmina total de água proveniente das chuvas foi de $24,36 \mathrm{~mm}$. Apenas cinco dias apresentaram umidade relativa do ar igual ou abaixo de $30 \%$ (Figura 2) durante todo o ciclo de condução da cultura. O valor médio para essa característica foi de $53.4 \%$.

Ao se observar a temperatura média diária durante $\mathrm{O}$ experimento, ocorreu uma variação entre 16,45 e $26,7{ }^{\circ} \mathrm{C}$, 
conforme mostrado pela Figura 3, sendo que o valor médio ao longo desse período foi de $22,8{ }^{\circ} \mathrm{C}$.

Para as variáveis estudadas de altura de plantas, massa seca de raízes e $\mathrm{N}$ foliar, apenas as duas últimas apresentaram diferença significativa, sendo observada para o fator isolado de doses de nitrogênio. O maior acúmulo de massa seca nas raízes de beterraba foi observado quando administrada a dose máxima de $200 \mathrm{~kg} \mathrm{ha}^{-1}$, devido ao nitrogênio proporcionar um aumento na massa seca de raízes, conforme Figura 4.

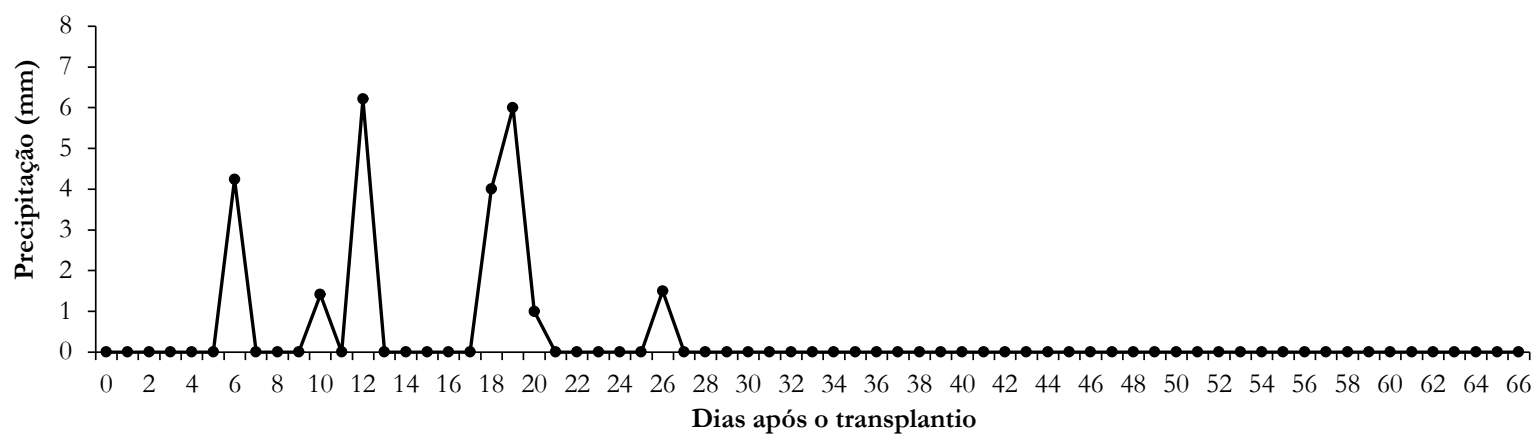

Figura 1. Precipitação diária $(\mathrm{mm})$ durante a condução do experimento.

Figure 1. Daily rainfall $(\mathrm{mm})$ the experiment while conducting.

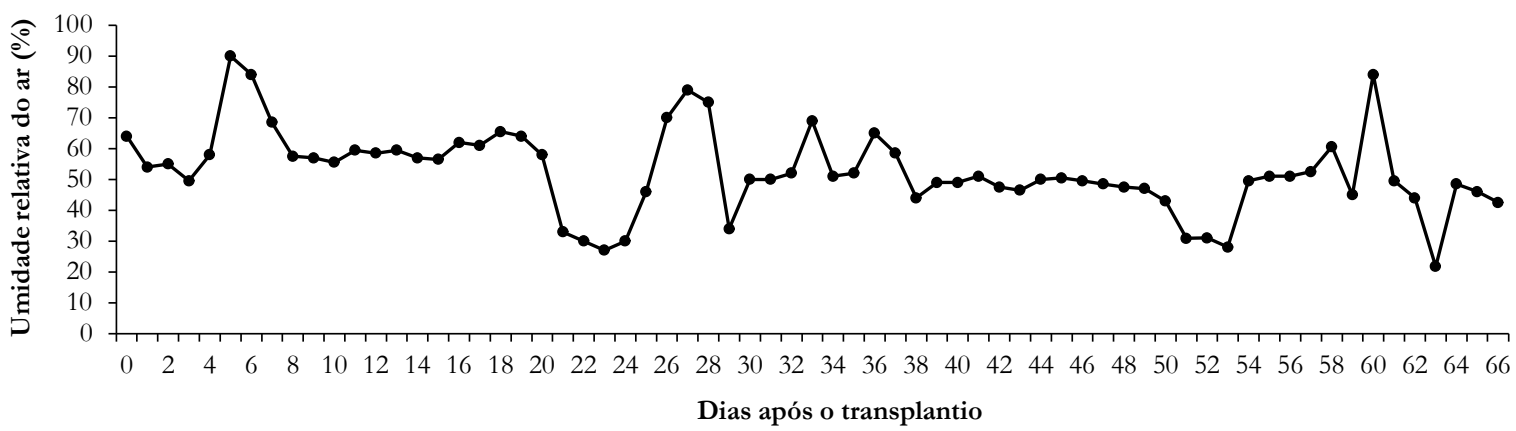

Figura 2. Umidade relativa do ar diária (\%) durante a condução do experimento.

Figure 2. Daily relative air humidity (\%) while the experiment conducting.

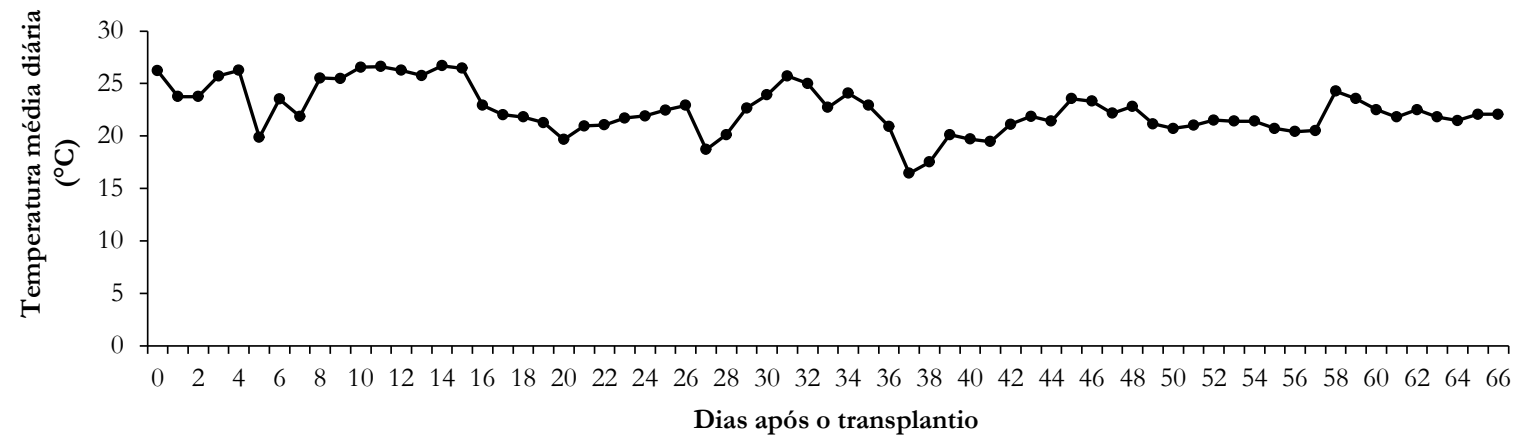

Figura 3. Temperatura média diária $\left({ }^{\circ} \mathrm{C}\right)$ durante a condução do experimento.

Figure 3. Daily average temperature $\left({ }^{\circ} \mathrm{C}\right)$ while the experiment conducting.

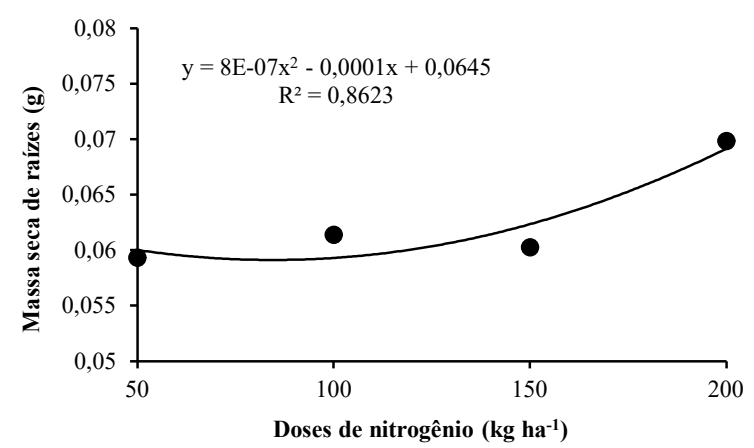

Figura 4. Massa seca de raízes para doses de $\mathrm{N}$ na condução do experimento.

Figure 4. Roots dry mass for doses of $\mathrm{N}$ in experiment conducting.
A Figura 5 mostra o comportamento do teor de nitrogênio nas folhas de beterraba aos 62 dias após o transplante das mudas na área experimental. Ao observá-la, nota-se que a dose de nitrogênio que proporcionou o maior teor foliar foi de 145,87 $\mathrm{kg}$ de $\mathrm{N} \mathrm{ha}^{-1}$.

Em relação às variáveis sólidos solúveis totais (SST), $\mathrm{pH}$ e acidez das raízes de beterraba, nota-se que houve diferença estatística significativa apenas para a variável SST, ocorrendo para os fatores de variação fator $\mathrm{f}$ e a interação entre as doses de $\mathrm{N}$ e fator $\mathrm{f}$.

Considerando as diferenças inerentes à interação entre as doses de $\mathrm{N}$ e fator $\mathrm{f}$, estas ocorrem apenas quando a irrigação foi realizada nos tratamentos com fatores $f$ de 0,3 e 0,7 ; e para os fatores $\mathrm{f}$, na maioria das doses de $\mathrm{N}$, com exceção da dose de $50 \mathrm{~kg} \mathrm{ha}{ }^{-1}$. 


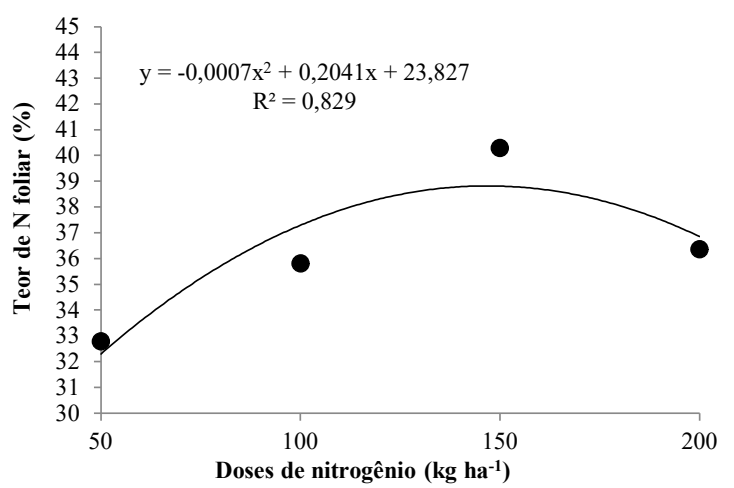

Figura 5. Nitrogênio foliar para doses de $\mathrm{N}$ na condução do experimento.

Figure 5. Leaf nitrogen for doses of $\mathrm{N}$ in experiment conducting.

Quanto às médias de sólidos solúveis totais em função das doses de $\mathrm{N}$ para o fator 0,3 , houve um acréscimo nos teores acumulados de SST, no intervalo da dose de $50 \mathrm{~kg} \mathrm{ha}$ 1 até a dose de 126, $25 \mathrm{~kg} \mathrm{ha}^{-1}$ de N. Após este intervalo de adubação, até a dose de $200 \mathrm{~kg} \mathrm{ha}^{-1}$, os valores acumulados decresceram. Já em função das doses de $\mathrm{N}$ para o fator 0,7 (Figura 6), observa-se que quanto maior for à dose de $\mathrm{N}$ aplicada menor é o acumulo dos teores de SST.

Ao aplicar uma dose de $100 \mathrm{~kg} \mathrm{ha}^{-1}$ de $\mathrm{N}$, observa-se que as médias do SST na cultura da beterraba crescem até um valor correspondente do fator $\mathrm{f}$ de 0,41 . Ao aumentar este valor do fator, há decréscimo na absorção de $\mathrm{N}$ pelas plantas, ocorrendo menor acúmulo de SST nas raízes de beterraba colhidas (Figura 7).

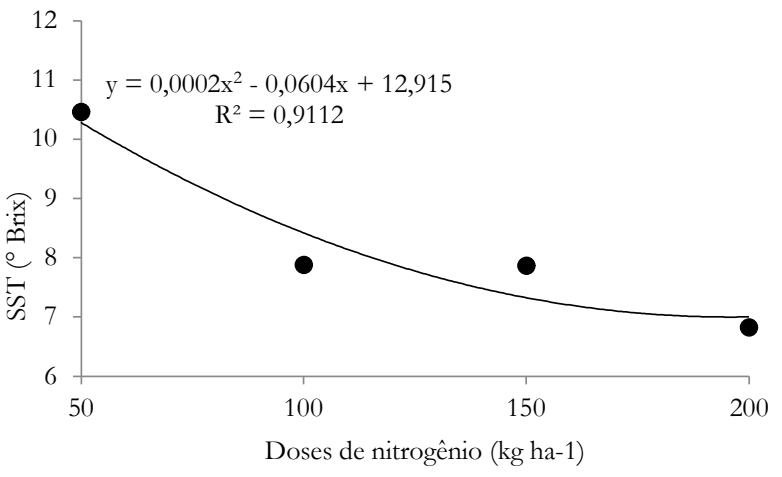

Figura 6. Valores médios de SST para o fator 0,7 em função das doses de $\mathrm{N}$.

Figure 6. SST average values for factor 0.7 in function of $\mathrm{N}$ doses.

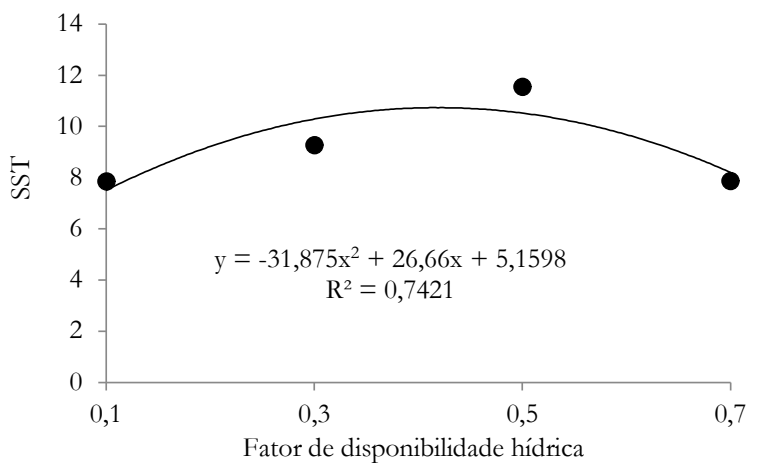

Figura 7. Valores médios de SST na dose de $\mathrm{N}$ de $100 \mathrm{~kg} \mathrm{ha}^{-1} \mathrm{em}$ função dos fatores de disponibilidade hídrica.

Figure 7. SST average values at $100 \mathrm{~kg} \mathrm{ha}^{-1} \mathrm{~N}$ dose in function of water availability factors.
Na Figura 8 são apresentados os resultados de SST nas raízes de beterraba em função do fator $\mathrm{f}$, quando aplicado uma dose de $150 \mathrm{~kg} \mathrm{ha}{ }^{-1}$ de N. Constata-se que os valores médios de SST são crescentes até o fator $\mathrm{f}$ de 0,33 , havendo decréscimo a partir desse valor do fator $\mathrm{f}$.

Aplicando uma dose de $200 \mathrm{~kg} \mathrm{ha}^{-1}$ de $\mathrm{N}$, há um acréscimo nas médias do SST até o fator $\mathrm{f}$ de 0,19 , conforme Figura 9. A partir desse valor, ocorre o decréscimo no acúmulo de SST nas raízes de beterraba.

Para a variável produtividade, houve efeito significativo apenas para doses de $\mathrm{N}$ isoladamente. $\mathrm{O}$ crescimento da produtividade ocorre de maneira linear, até a dose de experimentação máxima de $\mathrm{N}\left(200 \mathrm{~kg} \mathrm{ha}^{-1}\right)$, como pode ser observado na Figura 10.

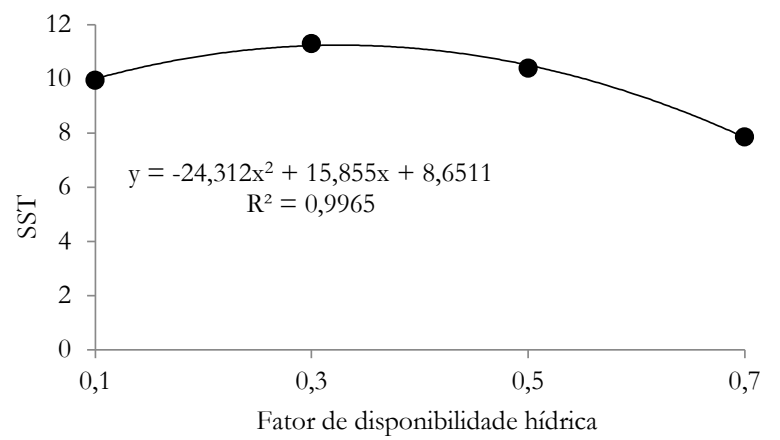

Figura 8. Valores médios de SST na dose de $\mathrm{N}$ de $150 \mathrm{~kg} \mathrm{ha}^{-1} \mathrm{em}$ função dos fatores de disponibilidade hídrica.

Figure 8. SST average values at $150 \mathrm{~kg} \mathrm{ha}^{-1} \mathrm{~N}$ dose in function of water availability factors.

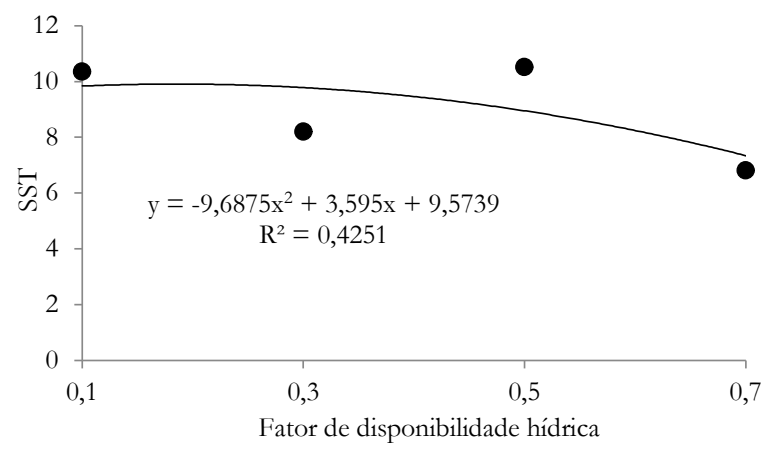

Figura 9. Valores médios de SST a dose de N de $200 \mathrm{~kg} \mathrm{ha}^{-1} \mathrm{em}$ função dos fatores de disponibilidade hídrica.

Figure 9. SST average values at $200 \mathrm{~kg} \mathrm{ha}^{-1} \mathrm{~N}$ dose in function of water availability factors.

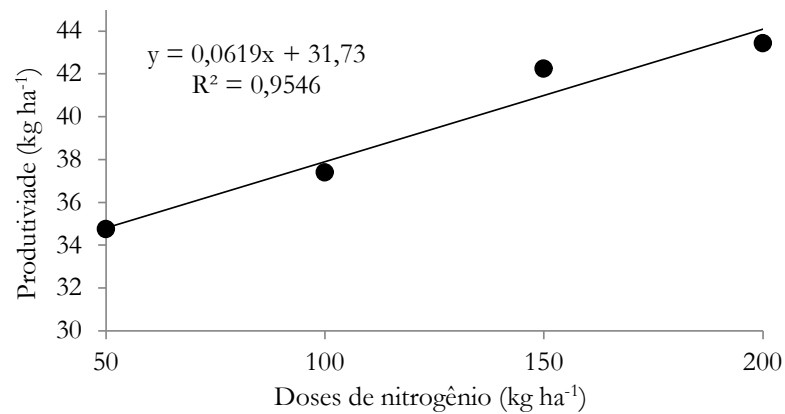

Figura 10. Produtividade para doses de $\mathrm{N}$ na condução do experimento.

Figure 10. Productivity for doses of $\mathrm{N}$ in conducting of the experiment. 


\section{DISCUSSÃO}

Os resultados de teor de nitrogênio foliar encontrados pelo presente trabalho são coerentes com o estudo de Oliveira et al. (2017), onde, avaliando doses de nitrogênio associadas ou não a adubações com enxofre $e$ micronutrientes em beterraba, concluíram que conforme se aumentam as doses utilizadas na adubação nitrogenada, há um incremento, até certo ponto, da massa fresca das folhas. O nitrogênio, no metabolismo das plantas, exerce importante função na divisão e expansão celular, portanto o teor de $\mathrm{N}$ foliar está diretamente relacionado com o desenvolvimento da parte aérea.

Com o desenvolvimento vegetativo da parte aérea, estudos demonstram que há crescimento da área foliar. De acordo com Sediyama et al. (2011), foi verificado diferença no desenvolvimento da altura, ao se testar coberturas de plantas no cultivo de beterraba. Consequentemente, as maiores plantas, ou seja, as de maior altura, tiveram maior área foliar. Esta área foliar proporciona maior transformação de energia solar em energia química, e a planta a utiliza em todo o seu metabolismo. O desenvolvimento limitado das folhas se dá pela economia de energia que seria gasta para a produção da mesma, e sim a reservando para o uso de suas funções fisiológicas enquanto a disponibilidade hídrica seja pouca (TAIZ; ZEIGER, 2009).

Carvalho et al. (2011), ao estudar lâminas de irrigação na cultura da beterraba, concluíram que as lâminas de água não proporcionaram efeito na massa seca das raízes. Isso ocorre devido à dificuldade que as raízes de beterraba têm de absorver água, quando a tensão de água no solo está alta. Nessa situação, há maior gasto de energia na absorção de água e também de nutrientes. Esse gasto de energia pode ter consequência no final do ciclo da cultura, ou seja, conforme a intensidade, é capaz de reduzir na produção e qualidade do produto colhido (TAIZ; ZEIGER, 2009).

Quando se diz respeito à adubação nitrogenada, doses muito altas somadas à baixa eficiência de absorção pelas plantas geram a possibilidade de perda para o ambiente, principalmente por lixiviação e volatilização. (XAVIER et al., 2008). Ao pesquisar a adubação nitrogenada em outras hortaliças, Porto et al. (2011) utilizaram um intervalo muito grande de doses na adubação na cultura da abobrinha, onde o mesmo variou de 0 a $400 \mathrm{~kg} \mathrm{ha}^{-1}$ de $\mathrm{N}$, apresentando crescente concentração de $\mathrm{N}$ foliar conforme o aumento da dose aplicada na cultura até os $400 \mathrm{~kg} \mathrm{ha}{ }^{-1}$.

Em relação às análises bromatológicas, outros autores, em experimentação com beterraba, não encontraram resultado significativo. Silva et al. (2015), testando lâminas de água e níveis de salinidade na beterraba, identificaram resultados semelhantes ao presente trabalho - o teor de sólidos solúveis totais não sofreu influência das lâminas de irrigação. Resultados equiparáveis foram encontrados também por Barreto et al. (2013), onde, estudando doses de nitrogênio $\left(0,25,50,75,100\right.$ e $\left.150 \mathrm{~kg} \mathrm{ha}^{-1} \mathrm{de} \mathrm{N}\right)$ nas cultivares de beterraba Early Wonder e Itapuã, constataram que os teores de SST, pH e acidez das raízes não são influenciadas pela variação das doses.

Tivelli et al. (2011) relatam que o cultivo da beterraba deve ser em condições ambientais em que a temperatura média anual seja inferior a $25^{\circ} \mathrm{C}$ para que não haja queda de produtividade. Em contrapartida, o presente trabalho mostra que houve variações acima de $25^{\circ} \mathrm{C}$, e ainda assim ocorreu uma boa produtividade de raízes. Pelo fato de ser uma hortaliça que requer muitos cuidados durante o sistema de produção, Tullio et al. (2013), relataram que em condições não apropriadas, como a estação do verão, que se tem alta temperatura e excesso de chuva, a produtividade pode reduzir em até $50 \%$.

O acúmulo linear de massa seca das raízes e a produtividade estão correlacionados, pois, quanto maior for o acúmulo de massa seca, maior será o peso das raízes, e, consequentemente, maior é a produtividade da cultura. Os resultados referentes à produtividade apresentados pelo presente trabalho corroboram com àqueles encontrados por Damasceno, Guimarães, Guimarães (2011), no qual, estudando a influência de doses de nitrogênio (0, 100, 200 e $300 \mathrm{~kg} \mathrm{ha}^{-1}$ de N) na cultivar de beterraba Early Wonder Stays Green, concluíram que há um crescimento linear de tal variável conforme há um aumento nas doses.

\section{CONCLUSÕES}

A dose de $150 \mathrm{~kg}$ de $\mathrm{N} \mathrm{ha}^{-1}$ oportunizou maior acúmulo de $\mathrm{N}$ foliar; a dose de $150 \mathrm{~kg}$ de $\mathrm{N} \mathrm{ha}^{-1}$ juntamente ao fator $\mathrm{f}$ de 0,3 proporcionaram maiores teores de SST nas raízes; e, por fim, o fator $\mathrm{f}$ de 0,7 , associado à dose de $200 \mathrm{~kg}$ de $\mathrm{N}^{-}$ ${ }^{1}$, possibilitaram maior produtividade.

\section{REFERÊNCIAS}

A.O.A.C. Official methods of analysis of the Association of Official Analytical Chemists. 16 ed. Arlington: Ed. Patrícia Cuniff, v. 2, p. 37-10, 42-2, 1997.

AGRISTAR. Semente beterraba Early Wnder Super Tall Top. 2019. Disponível em: <https://agristar.com.br/topseed/beterraba/earlywonder-super-tall-top/48/> Acesso em: 19 nov. 2019.

BARRETO, C. R.; ZANUZO, M. R.; WOBETO, C.; DA ROSA, C. C. B. Produtividade e qualidade da beterraba em função da aplicação de doses e nitrogênio. Revista Brasileira Multidisciplinar, [S. 1.], v. 16, n. 1, p. 145158, 2013.

CARVALHO, L. G.; RIOS, G. F. A.; MIRANDA, W. L.; CASTRO NETO, P. Evapotranspiração de referência: uma abordagem atual de diferentes métodos de estimativa. Pesquisa Agropecuária Tropical, Goiânia, v. 41, n. 3, p. 456-465, 2011.

COMISSÃO DE FERTILIDADE DO SOLO DO ESTADO DE MINAS GERAIS. Recomendações para o uso de corretivos e fertilizantes em Minas Gerais: $\mathbf{5}^{\mathbf{a}}$ aproximação. Viçosa, MG: UFV, 1999. 359p. COSTA, F. S.; SUASSUNA, J. F.; MELO, A. S.; BRITO, M. E. B.; MESQUITA, E. F. Crescimento, produtividade e eficiência no uso da água em bananeira irrigada no semiárido paraibano. Revista Caatinga, Mossoró, v. 25, n.4, p. 26-33, 2012.

DAMASCENO, L. A.; GUIMARÃES, M. A.; GUIMARÃES, A. R. Produtividade de beterraba em função de doses de nitrogênio. Horticultura Brasileira, Brasília, v. 29, n. 2 (Suplemento - CD ROM), 2011.

EPSTEIN, E.; BLOOM, A. J. Nutrição mineral de plantas: princípios e perspectivas. 2 ed. Londrina: Planta, 2006. 403p.

ESPIDULA, M. C.; ROCHA, V. S.; SOUZA, M. A.; GROSSI, J. A. S.; SOUZA, L. T. Doses e formas de aplicação de nitrogênio no desenvolvimento e produção da cultura do trigo. Ciência e Agrotecnologia, Lavras, v. 34, n. 6, p. 1404-1411, 2010.

FERREIRA, D. F. Estatística multivariada. Lavras: Editora UFLA, 2008. 662p. 
GOMES, R. F.; SILVA, J. P.; SILVA, V. F. A.; GUSMÃO, S. A. L.; SOUZA, G. T. Diferentes fontes de adubações foliares em chicória da Amazônia. Revista Verde, Mossoró, v. 7, n. 3, p. 73-78, 2012.

HARGREAVES, G. H.; SAMANI, Z. A. Reference crop evapotranspiration from temperature. Applied Engineering Agricuture, v. 1, n. 2, p. 96-99, 1985.

INSTITUTO ADOLFO LUTZ. Métodos físico-químicos para análise de alimentos. São Paulo: Instituto Adolfo Lutz, 1985. 1020p.

LIMA JUNIOR, J. A.; SILVA, A. L. P. GUEDES, M. G. M. Qualidade de raízes de cenoura em função de diferentes tensões de água no solo. Engenharia Ambiental, Espírito Santo do Pinhal, v. 9, n. 1, p. 26-35, 2012.

LOPES, O. D.; KOBAYASHI, M. K.; OLIVEIRA, F. G.; ALVARENGA, I. C. A; MARTINS, E. R.; CORSATO, C. E. Determinação do coeficiente de cultura $(\mathrm{Kc})$ e eficiência do uso da água do alecrim-pimenta irrigado. Revista brasileira de Engenharia Agrícola e Ambiental, Campina Grande, v. 15, p. 548-553, 2011.

MANTOVANI, E. C.; BERNARDO, S.; PALARETTI, L. F. Irrigação: princípios e métodos. Ed. atual. e ampl. Viçosa, Viçosa: UFV, ed. 2, p. 355, 2009.

MELO, A. S.; SUASSUNA, J. F.; FERNANDES, P. D.; BRITO, M E. B.; SUASSUNA, A. F.; AGUIAR NETO, A. O. Crescimento vegetativo, resistência estomática, eficiência fotossintética e rendimento do fruto da melancieira em diferentes níveis de água. Acta Scientiarum Agronomy, Maringá, v. 32, n. 1, p. 73-79, 2010.

OLIVEIRA, R. J. P.; GATIBONI, L. C.; BRUNETTTO, G.; MIQUELLUTI, D. J.; VALICHESKI, R. R. Resposta da beterraba a adubação com nitrogênio, enxofre e micronutrientes em um Cambissolo Háplico. Horticultura Brasileira, Brasília, v. 35, n. 1, p. 63-68, 2017.

PARIDA, A. K.; DAS, A. B. Salt tolerance and salinity effects on plants: A review. Ecotoxicology and Environmental Safety, v. 60, p. 324-349, 2005.

PORTO, L.; PUIATTI, M.; FONTES, P. C. R.; CECON, P. R.; ALVES, J. C.; ARRUDA, J. A. Índice SPAD para o diagnóstico do estado de nitrogênio na cultura da abobrinha. Horticultura Brasileira, Brasília, v. 29, n. 3, p. 311-315, 2011.

RESENDE, G. M.; CORDEIRO, G. G. Uso da água salina e condicionador de solo na produtividade de beterraba e cenoura no Semi-Árido do Submédio São Francisco. Petrolina: Embrapa Semi-Árido, 2007. (Comunicado Técnico, 128).

RODELA, A. A.; LAVORENTI, A.; ALVES, M. E.; KAMOGAWA, M. Y. Disciplina LCE108 - Química inorgânica e analítica. Guia de aulas práticas e exercícios. Universidade de São Paulo - Escola Superior de Agricultura Luiz de Queiroz. Piracicaba (SP), 2007.

SEBRAE. Beterraba Saiba como cultivar hortaliças e colher bons negócios. Série Agricultura Familiar; Brasília: Serviço Brasileiro de Apoio às Micro e Pequenas Empresa. SGAS 604/605. Módulos 30 e 31, 2011.

SEDIYAMA, M. A. N.; SANTOS, M. R.; VIGIGAL, S. M.; SALGADO, L. T. Produtividade e exportação de nutrientes em beterraba cultivada com cobertura morta e adubação orgânica. Revista Brasileira de Engenharia Agrícola e Ambiental. Campina Grande, v. 15, n. 9, p. 883-33, 2011.
SILVA, F. B.; LÚCIO, J. C. B.; SILVA, J. C.; SILVA, C. B.; ALVES, C. F. G.; SANTOS, M. A. L. Teor de sólidos solúveis totais e intensidade de verde no desenvolvimento da beterraba em função de lâminas de água e níveis de salinidade. XXV CONIRD - Congresso Nacional de Irrigação e Drenagem. 08 a 13 de novembro de 2015, UFS - São Cristóvão/SE, 2015.

SOUZA, A. P.; PEREIRA, J. B. A.; SILVA, L. D. B.; GUERRA, J. G. M.; CARVALHO, D. F. Evapotranspiração, coeficientes de cultivo e eficiência do uso da água da cultura do pimentão em diferentes sistemas de cultivo. Acta Scientiarum. Agronomy, Maringá, v. 33, n. 1, p. 15- 22, 2011.

SOUZA, J. A.; BUZETTI, S.; TEIXEIRA FILHO, M.C.M.; ANDREOTTI, M.; SÁ, M. E.; ARF, O. Adubação nitrogenada na cultura do milho safrinha irrigado em plantio direto. Bragantia, Campinas, v. 70, p. 447-54, 2011.

TAIZ, L.; ZEIGER, E. Fisiologia vegetal. 4.ed. Porto Alegre: Artmed, 2009. 819p.

TIVELLI, S.; FACTOR, T. L.; TERAMOTO, J. R. S.; FABRI, E. G.; MRAES, A. R. A.; TRANI, P. E.; MAY, A. Beterraba, do plantio à comercialização. Campinas: IAC, 2011. 45p. (Série Tecnologia APTA, Boletim Técnico IAC, 210)

TORRES, J. L. R.; PEREIRA, M. G.; ANDRIOLI, I.; POLIDORO, J. C.; FABIAN, A. J. Decomposição e liberação de nitrogênio de resíduos culturais de plantas de cobertura em um solo de cerrado. Revista Brasileira de Ciência do Solo, Viçosa, v. 29, n. 4, jul. 2005.

TULLIO, J. A.; OTTO, R. F.; BOER, A.; OHSE, S. Cultivo de beterraba em ambientes protegido e natural na época de verão. Revista Brasileira de Engenharia Agrícola e Ambiental, Campina Grande, v. 17, n. 10, p. 1074-1079, 2013.

XAVIER, T. F.; ARAÚJO, A. S. F.; SANTOS, V. B.; CAMPOS, F. L. Inoculação e adubação nitrogenada sobre a nodulação e a produtividade de grãos de feijãocaupi. Ciência Rural, v. 38, n. 7, p. 2037-2041, 2008. 